\title{
BAÇO MIGRATÓRIO EM HÉRNIA PARAESTOMAL
}

\section{WANDERING SPLEEN IN PARASTOMAL HERNIA}

\section{César Guerreiro de Carvalho - ACBC - RJ' ${ }^{1}$; Carlos Eduardo Pereira do Vale - ACBC - RJ' Paulo César de Castro Jr. - TCBC - RJ33 ; Thiago Borges Frade ${ }^{4}$}

\section{INTRODUÇÃO}

O baço migratório é uma condição rara na prática médica e o seu achado no interior de uma hérnia paraestomal é inédito na literatura disponível. Apresentamos um caso em que a correção da distopia esplênica e da hérnia paraestomal foram resolvidos por via videolaparoscópica, com bom resultado e rápida recuperação.

\section{RELATO DO CASO}

Paciente de 85 anos, feminina, portadora de volumosa hérnia paraestomal. Iniciou seu quadro há 32 anos após uma operação de Miles devido a um adenocarcinoma de canal anal. Apesar da evolução favorável, a paciente notou o surgimento de uma hérnia paraestomal. $\mathrm{O}$ aumento gradativo da hérnia levou a um quadro de dor abdominal intermitente, volumoso abaulamento abdominal e incapacidade progressiva para as atividades cotidianas. Ao exame físico havia uma volumosa e irredutível hérnia paraestomal. A tomografia computadorizada demonstrou hérnia paraestomal gigante,

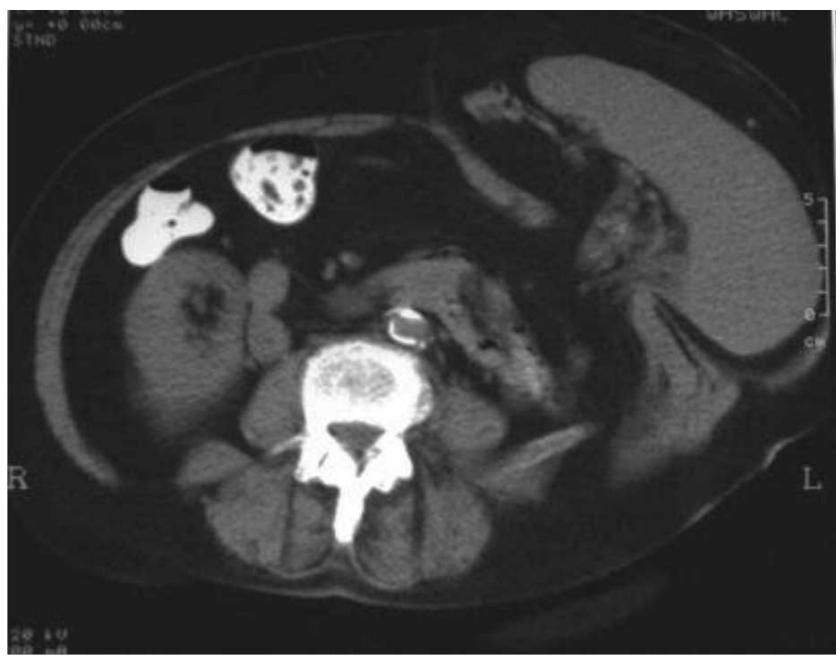

Figura 1 - Hérnia paraestomal gigante, contendo alças intestinais e imagem compatível com baço. contendo alças intestinais e imagem compatível com baço (Figura 1). Foi indicada a correção cirúrgica por videolaparoscopia na técnica denominada nó de gravata ${ }^{1}$.

O inventário da cavidade evidenciou volumosa hérnia paraestomal com um amplo orifício herniário, contendo alças de delgado e todo o baço, além de parte do grande omento (Figura 2). Realizada a lise das aderências para permitir a colocação intraperitoneal da tela. Redução do grande omento e das alças de delgado, o que permitiu a redução espontânea do baço. Colocação intraperitoneal de tela de politetrafluoretileno expandido (ePTFE) - (GORE-TEX® Biomaterial; W. L. Gore \& Associates, Flagstaff, AZ) seguindo a técnica descrita por Carvalho et al ${ }^{1}$.

A paciente apresentou boa recuperação pós-operatória com alta em 24 horas e retorno às atividades cotidianas, sem restrição, após a primeira semana da cirurgia.

\section{DISCUSSÃO}

O baço migratório, também denominado baço ectópico ou ptose esplênica é uma condição raramente obser-

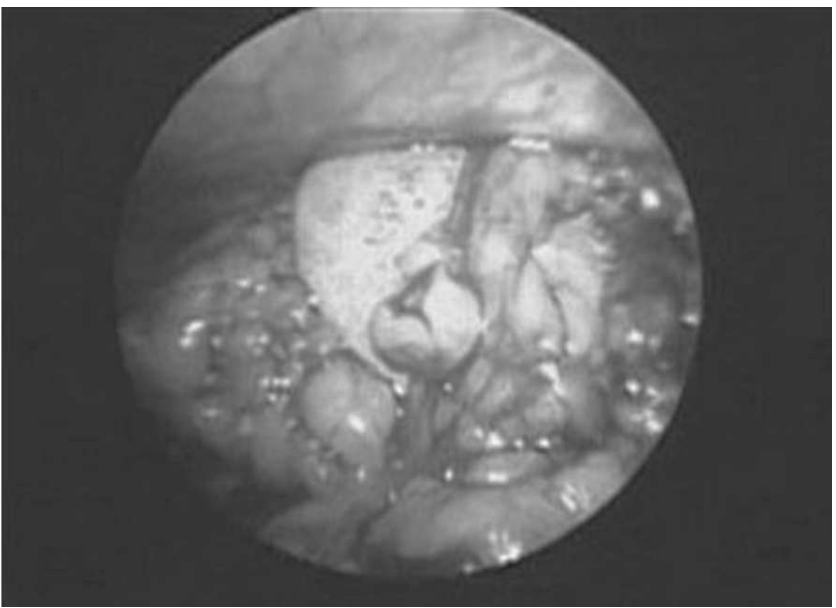

Figura 2 - Volumosa hérnia paraestomal com um amplo orifício herniário, contendo alças de delgado e todo o baço, além de parte do grande omento.

1. Chefe da Clínica de Proctologia Cesar Guerreiro; Titular de Proctologia da SBCP.

2. Staff da Clínica de Proctologia Cesar Guerreiro; Especialista de Proctologia pela SBCP.

3. Staff da Clínica de Proctologia Cesar Guerreiro; Titular de Proctologia da SBCP.

4. Staff da Clínica de Proctologia Cesar Guerreiro; Residente de Proctologia do Hospital Naval Marcílio Dias.

Recebido em 13/02/2006

Aceito para publicação 21/03/2006

Conflito de interesse: nenhum

Fonte de financiamento: nenhuma

Trabalho realizado na Clínica de Proctologia Cesar Guerreiro, Rio de Janeiro - RJ. 
vada. O primeiro relato, descrito por Van Horne ${ }^{2,3}$, ocorreu em 1667. Acomete pacientes de três meses a 80 anos, sendo mais comum entre crianças e em mulheres entre 20 a 40 anos $^{2}$. Trabalhos sobre esplenectomia demonstram uma incidência menor que $0,5 \%{ }^{3}$. A etiologia parece estar ligada à falha da fusão do mesogástrio com a parede posterior do abdome no segundo mês da vida embrionária ${ }^{3-5}$. A multiparidade também parece exercer alguma influência - fato observado epidemiologicamente. Um longo pedículo vascular predispõe a torção do órgão, o que pode trazer dor aguda, crônica ou intermitente ${ }^{3,4}$. A torção permanente do pedículo pode levar ao infarto esplênico. Também foram relatados casos de pancreatite caudal e sintomas de compressão gástrica ${ }^{2,4}$. O tratamento pode ser: a simples observação clínica, quando assintomático, ou a cirurgia - falta consenso para pacientes adultos. A operação pode ser a esplenectomia, esplenectomia parcial com fixação do restante do baço no diafragma ou na parede abdominal e, ainda, a fixação de todo o baço mediante uso de tela ou por um "envelope" de peritônio parietal ${ }^{2-5}$.

A hérnia paraestomal é uma complicação bastante comum e quase inevitável ${ }^{1}$. O seu tratamento evoluiu desde o simples reposicionamento do estoma ao uso de material sintético para a correção do defeito herniário. A utilização da técnica videolaparoscópica traz consigo a menor morbidade do acesso laparoscópico, a possibilidade de redução do conteúdo herniário pelo pneumoperitônio e o manuseio da tela em um ambiente livre de contaminação. Essa técnica possibilita uma boa resolubilidade, com baixos índices de complicações e rápida recuperação ${ }^{1}$.

No caso apresentado a tática empregada possibilitou a resolução das duas doenças simultaneamente e com uma recuperação precoce da paciente.

\begin{abstract}
The authors report a case of a parastomal hernia that incarcerated a wandering spleen. We present a very rare case of an 85 year-old woman with a giant parastomal hernia. Computed tomography revealed a parastomal hernia with a wandering spleen inside. We introduce a different and simple alternative approach, with the smallest inconvenience as possible to solve the trouble. We carried out the treatment with a prosthetic repair closing the defect with ePTFE mesh, performed through a laparoscopic approach, intraperitoneal, like a tie and move the spleen back to its anatomical place. The result was excellent (Rev. Col. Bras. Cir. 2008; 35(5): 349-350).
\end{abstract}

Key words: Wandering spleen; Parastomal, hernia; Laparoscopy; Surgery.

\title{
REFERÊNCIA
}

1. Carvalho CG, Vale CEP, Castro Júnior PC. Tratamento cirúrgico da hérnia paraestomal por videolaparoscopia. Rev Bras Coloproct. 2004; 24(4):311-6.

2. Dahiya N, Karthikeyan D, Vijay S, Kumar T, Vaid M. Wandering spleen - unusual presentation and course of events. Ind J Radiol Imaging. 2002;12(3):359-62.

3. Lane TM, South LM. Management of a wandering spleen. J R Soc Med. 1999; 92(2):84-5.

4. López-Tomassetti F, Arteaga G, Martín M, Carrillo P. An unusual case of hemoperitoneum owing to acute splenic torsion in a child with immunoglobulin deficiency. J Postgrad Med. 2006; 52(1):412.

5. Jesus LE, Marinho EB, Júdice MM. Rotação gastro-esplênica inversa com ausência de rotação do intestino médio. Rev Col Bras Cir. 2004; 31(5):338-9.
Como citar este artigo:

Carvalho CG, Vale CE, Frade TB, Castro Jr PC. Baço migratório em hérnia paraestomal. Rev Col Bras Cir. [periódico na Internet] 2008; 35(5). Disponível em URL: http://www.scielo.br/rcbc

Endereço para correspondência:

Cesar Guerreiro de Carvalho

R.Siqueira Campos, 07/901 - Copacabana

22031-070 - Rio de Janeiro - RJ

E-mail: cesarguerreiro@terra.Com.br 